\title{
SISTEM INFORMASI BERBASIS WEB UNTUK PENGELOLAAN PENERIMA DANA ZAKAT, INFAQ DAN SEDEKAH
}

\author{
Syahidan Mushab Al-Zikri ${ }^{1)}$, Agus Wantoro ${ }^{2)}$, Zaenal Abidin ${ }^{3)}$ Jon Idrison Molina ${ }^{4)}$ \\ 1), 2) S1 Informatika, ${ }^{3)}$ S1 Sistem Informasi, Universitas Teknokrat Indonesia \\ 4) Teknik Informatika, Universitas Tribuana Kalabahi \\ 1), 2) 3) Jl. H.ZA Pagaralam, No 9-11, Labuhanratu,Bandarlampung \\ 4) Jl. Soekarno-Hatta Batunirwala, Kalabahi Alor, NTT \\ Email : syahidan.m.al@gmail.com ${ }^{1)}$, aguswantoro.ilkom@gmaill.com ${ }^{2)}$, \\ zabin@teknokrat.ac.id ${ }^{3)}$,jhonmolina8788@gmail.com ${ }^{4}$
}

\begin{abstract}
Abstrak
Penelitian ini dilakukan atas dasar kebutuhan akan adanya suatu sistem pengelolaan data penerima dana zakat, infaq dan sedekah yang dapat digunakan untuk mengelola data bagian pendayagunaan (PDG) pada Inisiatif Zakat Indonesia (IZI) Lampung. Dalam pembangunan sistem ini menggunakan metode model waterfall, serta analis sistem yang berjalan menggunakan analisis PIECES. Sistem pengelolaan data ini dirancang dengan alat pengembangan sistem UML (Unified Modeling Language) yang terdiri dari use case diagram, activity diagram, sequence diagram dan class diagram. Dalam membuat sistem ini menggunakan database MySQL dan text editor sublime text 3 dengan menggunakan framework laravel dan bahasa pemrograman PHP. Pada sistem ini terdapat system penginputan data, pencarian data, edit data, update data serta pembutan laporan yang memudahkan user dalam mencari data, mengubah data serta memperbaharui data yang diinginkan. Penerapan dari system ini memberikan kemudahan saat proses pengelolaan penginputan data penerima dana zakat, infaq dan sedekah serta pencarian data dan juga pembuatan laporan nya. Bagian bidang $P D G$ tidak harus mengirim data kepada pimpinan, karena data sudah ada di database, sehingga pimpinan bisa melihat informasi data kapan saja dan di mana saja menggunakan smartphone atau komputer.
\end{abstract}

Kata kunci : Framework Laravel, Dana Zakat, Infaq dan Sedekah

\section{Pendahuluan}

Lembaga Amil Zakat Nasional (LAZNAS) IZI, alasan paling penting mengapa IZI dilahirkan adalah adanya tekad yang kuat untuk membangun lembaga pengelola zakat yang otentik. Dengan fokus dalam pengelolaan zakat serta donasi keagamaan lainnya diharapkan IZI dapat lebih sungguh-sungguh mendorong potensi besar zakat menjadi kekuatan real dan pilar kokoh penopang kemuliaan dan kesejahteraan ummat melalui positioning lembaga yang jelas, pelayanan yang prima, efektifitas program yang tinggi, proses bisnis yang efisien dan modern, serta $100 \%$ shariah compliance sesuai sasaran ashnaf dan maqashid tujuan syariah. IZI Lampung mengelolan beberapa layanan seperti Zakat, Infaq dan
Sedekah. Zakat yaitu al-barokatu yang artinya keberkahan, al-namaa yang artinya pertumbuhan dan perkembangan, ath-thaharatu yang artinya mensucikan, dan ash-shalahu yang artinya keberesan (Hafidhuddin, 2012). Sedangkan Infaq berbeda dengan zakat, infaq merupakan pemberian yang tidak ada nishabnya sedangkan zakat sebaliknya. Besar kecilnya sangat bergantung kepada keuangan dan keikhlasan dalam memberi, yang terpenting adalah hak orang lain yang ada dalam harta kita sudah dikeluarkan (Hasan, 2016). Sedekah menurut terminology syariat, pengertian sedekah sama dengan pengertian infaq, termasuk juga hukum dan ketentuan-ketentuannya. Sedekah diartikan sebagai sebuah pemberian seseorang secara ikhlas kepada orang yang berhak menerima yang diiringi juga oleh pahala dari Allah (Ghazaly, 2010). Proses pengelolaan data IZI Lampung menggunakan Microsoft excel untuk pengelolaan data penerima dana zakat, infaq dan sedekah nya, mulai dari penginputan pengajuan layanan kemudian perhitungan dana yang sudah di terima oleh penerima manfaat, hingga proses pengelolaan laporan pendayagunaan dana nya. Penggunaan sistem aplikasi ini di rasa masih belum maksimal dalam pengelolaan data nya yang mana mengelola data dalam jumlah yang banyak. Permasalahan yang ada dalam sistem ini adalah : (1) tampilan penginputan data yang kurang efektif dan efisien, (2) membutuhkan waktu untuk pencarian data yang tersimpan di dalam folder-folder penyimpanan data di komputer, (3) tidak dapat melihat secara visual progres perkembangan data, (4) belum adanya sistem informasi online yang terpusat untuk bisa di akses kapan saja dan di mana saja untuk mempercepat dan mempermudah dalam mendapatkan informasi data penerima dana zakat, infaq dan sedekah di IZI Lampung. Pihak instansi menginginkan sistem pengelolaan data yang bisa menggantikan sistem yang sudah ada saat ini, dengan harapan memberi kemudahan dan kecepatan dalam mengelola data, untuk itu penulis mengusulkan penelitian dengan menerapkan framework laravel yang berjudul "Penerapan Framework Laravel untuk membangun Sistem Pengelolaan Data Penerima Dana Zakat, Infaq Dan Sedekah. 


\section{Pembahasan}

\subsection{Landasan Teori}

\section{a. Zakat}

Zakat yaitu al-barokatu yang artinya keberkahan, alnamaa yang artinya pertumbuhan dan perkembangan, ath-thaharatu yang artinya mensucikan, dan ash-shalahu yang artinya keberesan (Hafidhuddin, 2002). Sedangkan secara istilah, zakat adalah bagian dari harta dengan persyaratan tertentu, yang Allah SWT mewajibkan kepada pemiliknya, untuk diserahkan kepada yang berhak menerimanya, dengan persyaratan tertentu pula. Menurut bahasa, kata zakat berarti tumbuh, berkembang, subur atau bertambah. Menurut istilah, zakat dengan nama pengambilan tertentu dari harta yang tertentu, menurut sifat-sifat tertentu, dan untuk diberikan kepada golongan tertentu (Yasin, 2011)

\section{b. Penerima Zakat (Mustahik)}

Adapun yang berhak menerima zakat seperti yang tercantum dalam Al-Qur'an surat at-taubah ayat 60 dimana ayat tersebut menerangkan bahwa zakat fitrah maupun zakat mall diperuntukkan bagi 8 asnaf (golongan) yaitu :Orang fakir, yaitu orang yang amat sengsara hidupnya, tidak punya harta dan tenaga untuk memenuhi penghidupannya (Yasin, 2011)

\section{c. Infaq}

Infaq berbeda dengan zakat, infaq merupakan pemberian yang tidak ada nishabnya sedangkan zakat sebaliknya. Besar kecilnya sangat bergantung kepada keuangan dan keikhlasan dalam memberi, yang terpenting adalah hak orang lain yang ada dalam harta kita sudah dikeluarkan (Hasan, 2006)

\section{d. Sedekah}

Sedekah menurut terminology syariat, pengertian sedekah sama dengan pengertian infaq, termasuk juga hukum dan ketentuan-ketentuannya. Sedekah diartikan sebagai sebuah pemberian seseorang secara ikhlas kepada orang yang berhak menerima yang diiringi juga oleh pahala dari Allah (Ghazaly, 2010)

\subsection{Metode Pengembangan}

Model waterfall adalah model klasik yang bersifat sistematis dan berurutan dalam membangun software. Berikut ini adalah gambar fase-fase dalam model waterfall (Presman, 2010)

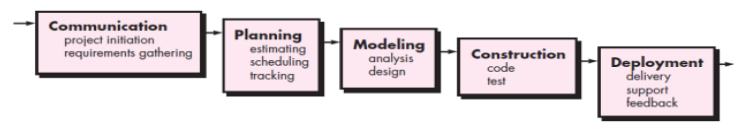

Gambar 1. Model Waterfall (Presman, 2010)

\section{a. Communication}

Kegiatan yang dilakukan pada tahap ini diawali dengan datang langsung ke IZI Lampung dan berkomunikasi dengan costumer untuk mendapatkan informasi dan datadata yang di perlukan, kemudian mengidentifikasi masalah dan kekurangan atau kelemahan pada sistem pengelolaan data penerima dana zakat, infaq dan sedekah di IZI Lampung yang sedang berjalan saat ini (Presman, 2010).

\section{b. Planning}

Pada tahap ini dilakukan perencanaan sistem yang akan kita buat dari hasil communication (analysis requirement) yang sudah di lakukan pada sistem pengelolaan data penerima dana zakat, infaq dan sedekah di IZI Lampung sebelumnya, tahapan ini akan menghasilkan dokumen user requirement atau bisa dikatakan sebagai data yang berhubungan dengan keinginan user dalam pembuatan system (Presman, 2010).

\section{c. Modelling}

Pada tahap ini pembuatan model dan desain antar muka (interface). Pemodelan menggunakan usecase diagram. Pemodelan ini menjelaskan secara garis besar actoractor yang terlibat di dalam sistem pengelolaan data penerima dana zakat, infaq dan sedekah di IZI Lampung. Pembuatan desain antarmuka (interface) sistem yang akan di buat (Presman, 2010).

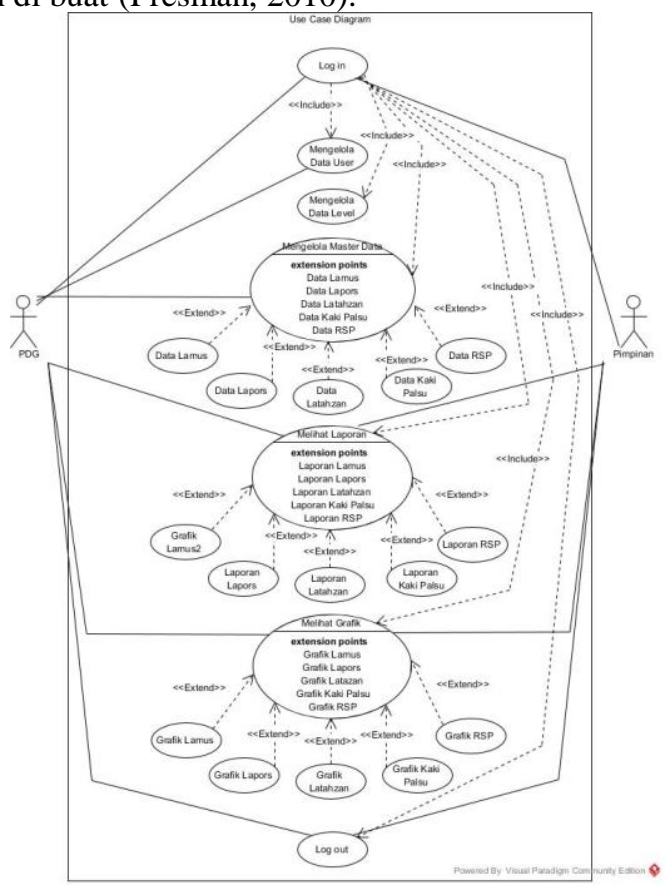

Gambar 2. Usecase Diagram

\section{d. Contruction}

Pada tahap ini mulai dilakukan pengkodingan untuk pembuatan sistem yang sudah di buatkan rancangan dan pemodelan nya. Setelah koding pembuatan program selesai maka akan dilakukan testing terhadap sistem yang telah dibuat tadi. Jika menemukan kesalahankesalahan terhadap sistem tersebut untuk kemudian bisa diperbaiki (Presman, 2010). 


\section{Halaman Beranda}

Pertama pada system adalah halaman beranda yang merupakan halaman pertama kali yang akan tampil setelah kita ketik link url nya di brouser. Dapat di lihat pada gambar 3 .

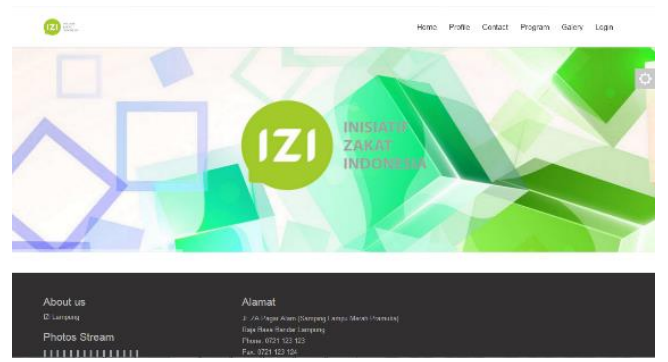

Gambar 3. Tampilan halaman home

\section{Halaman Form Login User}

Halaman ini merupakan validasi awal apakah kita mempunyai hak akses atau tidak pada sistem ini untuk masuk kedalam menu utama setelah berhasil log in, agar bisa log in kia harus memasukan e-mail dan password yang sudah di buat sebelumnya oleh user dengan benar. Dapat di lihat pada gambar 4.

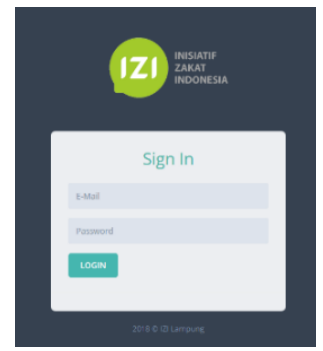

Gambar 4. Tampilan halaman log in user

\section{Halaman PDG}

Pada halaman ini merupakan halaman yang pertama kali akan tampil setelah kita berhasil $\log$ in dan akan menampilkan beberapa pilihan menu diantaranya : menu dashboard, menu master data, menu laporan dan menu grafik. Adapun informasi jumlah data dan total bantuan lamus, lapors, latahzan, kaki palsu dan RSP. Dapat di lihat pada gambar 5 .

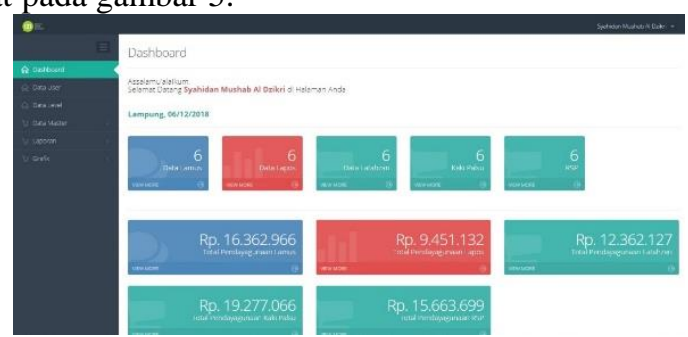

Gambar 5. Tampilan Halaman PDG

5. Tampilan Halaman PDG Form Menu Data Level Pada halaman ini PDG bisa menambah data level, mengedit data level, melihat list data level dan menghapus data level. Dapat di lihat pada gambar 6.

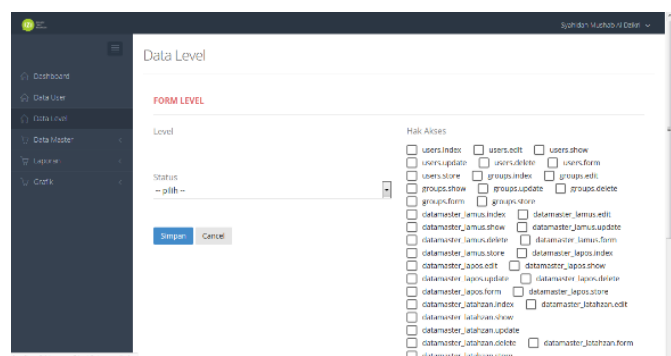

Gambar 6. Tampilan halaman PDG

\section{Halaman Laporan}

Pada halaman ini PDG bisa melihat list, melihat detail dan mencetak laporan lamus berdasarkan data lamus, lapors, latahzan, kaki palsu dan RSP yang di inginkan.

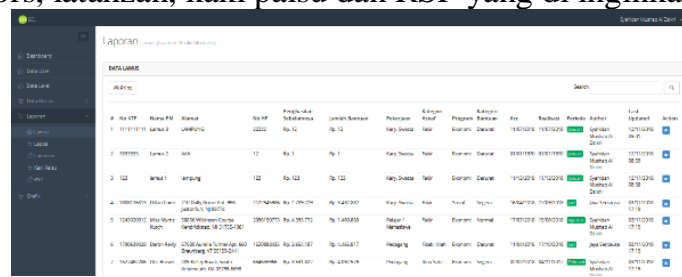

Gambar 7. Tampilan Laporan Lamus

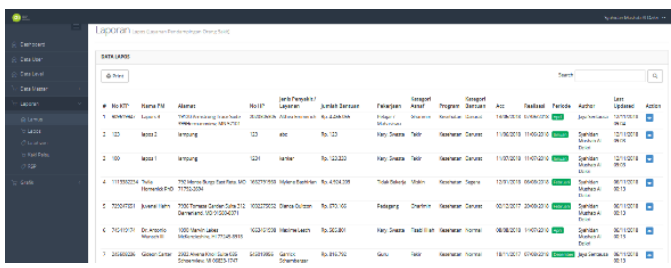

Gambar 8. Halaman Laporan Lapors

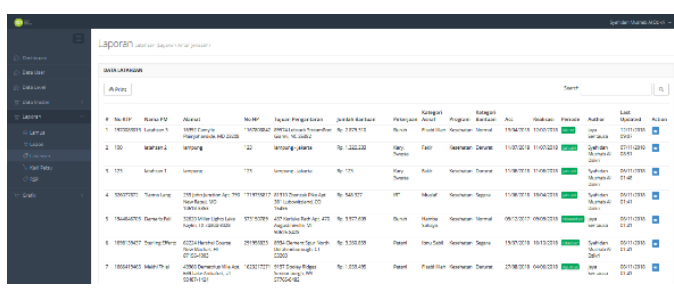

Gambar 9. Halaman Laporan Latahzan

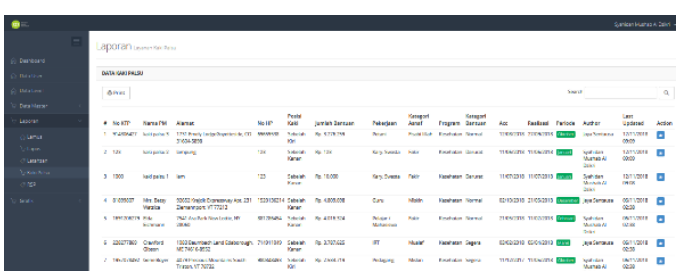

Gambar 10. Halaman Laporan Kaki Palsu

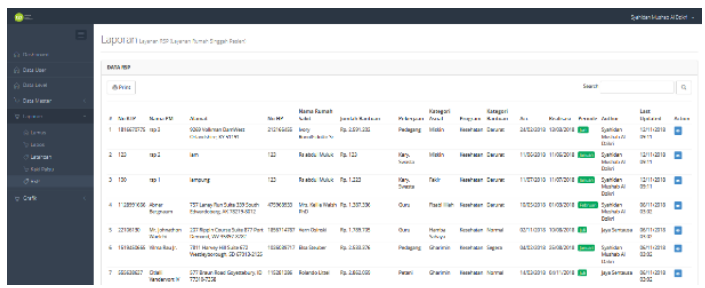

Gambar 11. Halaman Laporan RSP 


\section{Tampilan Halaman Grafik}

Pada halaman ini PDG bisa melihat grafik data lamus, lapors, latahzan, kaki palsu dan RSP berdasarkan periode.

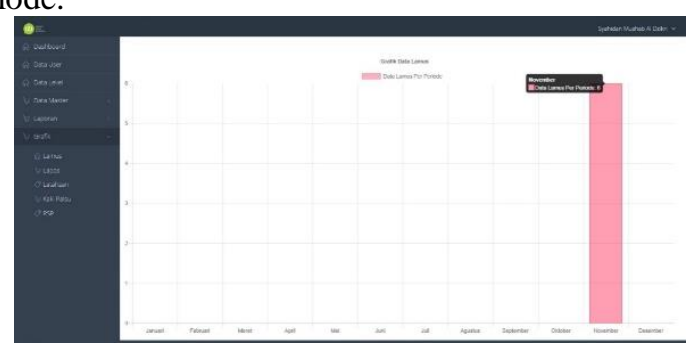

Gambar 12. Halaman Grafik Lamus

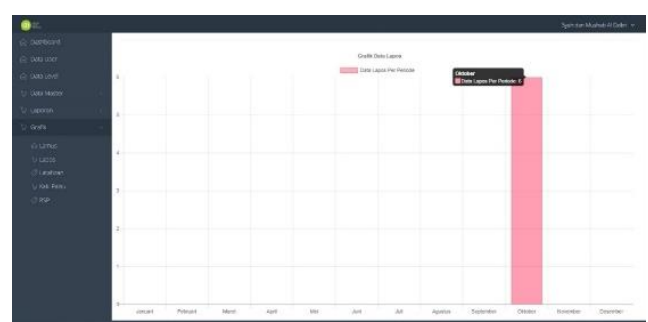

Gambar 13. Halaman Grafik Lapors

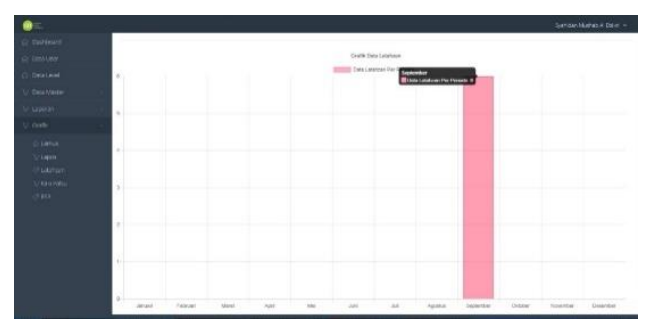

Gambar 14. Halaman Grafik Latahzan

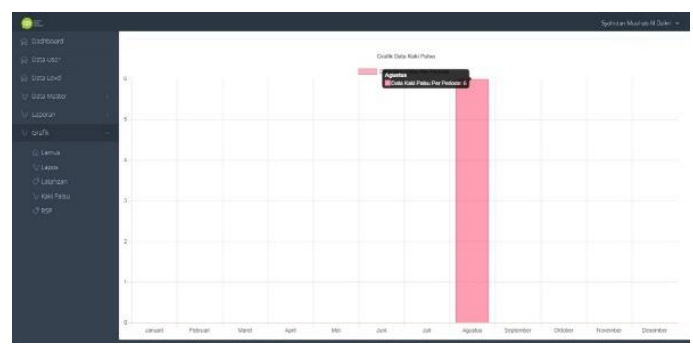

Gambar 15. Halaman Grafik Kaki Palsu

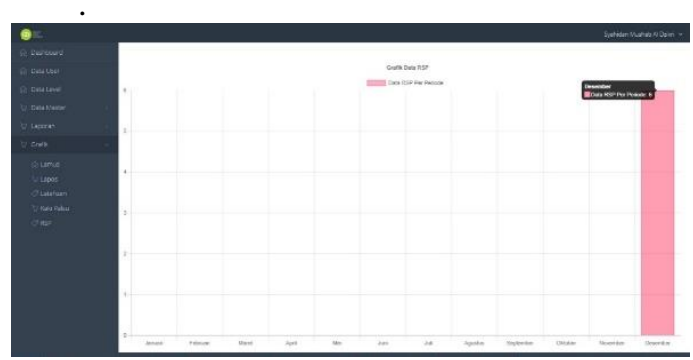

Gambar 16. Halaman Grafik RSP

\section{Kesimpulan}

Hasil penelitian dari analisis dan desain pada metode penelitian ini, maka dihasilkan sebuah system pengelolaan data penerima dana zakat, infaq dan sedekah di IZI Lampung. Penerapan sistem ini dapat membantu IZI Lampung dalam mengelola data penerima dana zakat, infaq dan sedekah. Sistem ini dapat membantu PDG dalam mengelola data lamus, lapors, latahzan, layanan kaki palsu, layanan RSP. Selain itu sistem pengelolaan data penerima dana zakat, infaq dan sedekah di IZI Lampung dapat disimpulkan sebagai berikut :

1. Penggunaan media online dapat mempermudah dalam mendapatkan informasi data penerima dana zakat, infaq dan sedekah pada IZI Lampung.

2. Penggunaan aplikasi web akan memaksimalkan proses pengelolaan data penerima dana zakat, infaq dan sedekah pada IZI Lampung agar lebih mudah proses penginputan data, pencarian data dan pembuatan laporan nya

3. Sistem yang di bangun menggunakan framewok laravel menggunakan alat pengembangan sistem UML (Unified Modeling Language). Basisdata yang digunakan MySQL dan tools Sublime Text 3 dan bahasa pemrograman PHP.

4. Sistem dapat mengelola data penerima layanan dengan cepat mulai dari penginputan data sampai pembuatan laporan nya.

5. Sistem dapat menampilkan data dalam bentuk visual grafik.

6. Sistem dapat di akses online oleh PDG dan pimpinan melalui media layanan internet (browser) dari komputer atau smartphone untuk mempercepat dan mempermudah dalam mengelola data dan mendapatkan informasi.

\section{Daftar Pustaka}

GHAZALY, ABDUL RAHMAN. 2010, Fiqih

Muamalat, Kencana, Jakarta

HASAN, M. ALI. 2006, Zakat Dan Infaq : Salah Satu Solusi Mengatasi Problema Sosial Di Indnesia, Kencana, Jakarta

\section{HAFIDHUDDIN, DIDIN. 2002, Zakat Dalam} Perekonomian Modern, Gema Insani Press. Jakarta

PRESSMAN, ROGER. S., 2010, Software Engineering a Practioner's Approach 7th Edition, McGraw - Hill Higher Education

YASIN, AHMAD HADI. 2011, Panduan Zakat Praktis, Dompet Dhuafa Republika, Jakarta 